\title{
Detection of Glass Fragment Based on Background Subtraction
}

\author{
Jiang yan ${ }^{1}$ and Fu Jiangwei ${ }^{2}$ \\ ${ }^{1}$ School of Software, Shenyang University of Technology, 110870 Shenyang, China \\ ${ }^{2}$ School of Information Science and Engineering, Shenyang University of Technology, 110870 Shenyang, \\ China
}

\begin{abstract}
An authoritative quality inspection system is implemented to safety glass in China, fragmentation test is one of the test methods. Presently, the work is finished by labor, which wastes time and energy, it's a reliable method to recognize crack lines of glass fragment by the means of digital image processing of which the image method which applies background subtraction makes some improvements on the account, in order to avoid appearing internal cavity of crack lines resulted by deduction operation, take advantage of improved Niblack binarization method and mathematical morphology operation to refill crack lines, then refine crack line and conduct a statistics of fragment amount. The experimental result shows that, the algorithm not only can make a precise statistics of fragment amount, but improve operating efficiency immensely.
\end{abstract}

Keywords: image processing, background subtraction, binarization, mathematical morphology.

\section{Introduction}

In order to guarantee the minimum damage of safety glass in application and destruction, China has implemented an authoritative quality test system, fragmentation test is one of the test methods, which is done by labor now, it's inefficient and effects the accuracy of test result ${ }^{[1]}$. Beyond seas, some scholars once made an analysis and discussion of glass fragment images after fragmentation test, but hadn't formed mature algorithm to describe the crack lines of fragment image accurately until now, this paper makes some discussion on the problem.

Tanaka $^{[2]}$ is the first to bring morphological operation into based image processing recognition of glass fragment. In order to detect and recognize glass fragment, Zhou Xueqin ${ }^{[3]}$, first made use of traditional edge detection operator to gain gradient image and used OTSU algorithm to make it binarization, then made a comparison of original gray scale image to fill crack lines so as to get uniform crack lines image of fragment, in the end, conducted reestablishment and inversion of gray scale, utilized based chain code watershed to converse split image, so that get the fragment amount. Fujita, proposed a way of using background subtraction to eliminate background noise: firstly, use median filter to smooth the whole image so as to get a strong smoothing of high-acuity objects, like crack line; then subtraction the smoothing image with original image, so that the new image highlights the crack line, while the noise like stain, spot in the fragment are weakened effectively. This approach has real applicability, which can realize effective deduction of most noise of glass fragment.

The writer of this paper makes an improvement of image noise deduction algorithm based on background subtraction in the operation of image noise deduction and crack like extraction, which means that, after accomplishment of background subtraction, make advantage of morphological operation to fill the internal hole of crack line so as to eliminate adverse effect of background subtraction, and to provide reference for the crack line recognition in practical engineering.

+Corresponding author: Jiang yan, Tel.: +86 13840229926

E-mail address: 165124472@qq.com. 


\section{The Gray Level Distribution Characteristics of Glass Fragment}

Set I as the original gray scale image, $p$ as a free pixel, $I(p)$ as the gray scale of the point. Seen from the analysis of original image and its gray scale histogram, the gray scale of the original image has outstanding features as follows: uniform distribution of gray scale in the interior part of glass fragment, which occupies a big proportion, the gray scale is among in some section, which can be expressed by two variable $\mathrm{k}_{1}, \mathrm{k}_{2}$, like $\left[\mathrm{k}_{1}, \mathrm{k}_{2}\right] . \mathrm{k}_{1}$ and $\mathrm{k}_{2}$ are determined by histogram of gray scale image of glass fragment. The crack line gray scale distribution of fragment is rather dispersal, uneven width and shade. This section can be expressed by two variable $\mathrm{k}_{3}, \mathrm{k}_{4}$, like $\left[\mathrm{k}_{3}, \mathrm{k}_{4}\right]$.

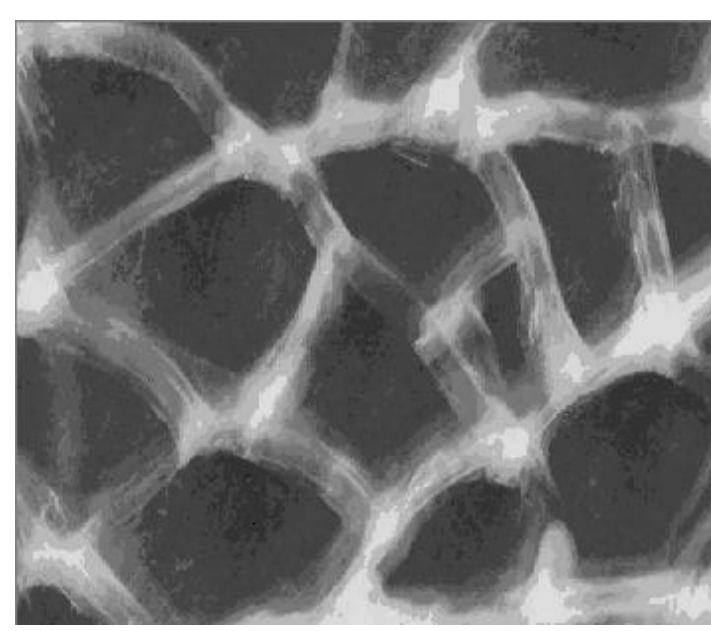

Fig.1: Gray scale of original image

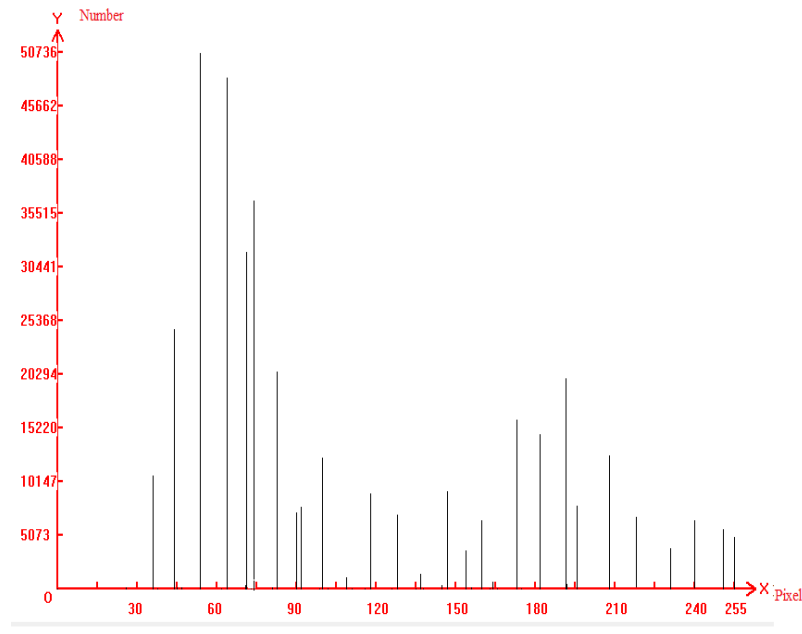

Fig.2: Gray histogram

Compared with the background in gray scale, divide image pixel into five subclass: (1)dark region $\mathrm{P}_{1}\left[0, \mathrm{k}_{1}\right] ;(2)$ background region $\mathrm{P}_{2}\left[\mathrm{k}_{1}, \mathrm{k}_{2}\right] ;(3)$ close-to-background noise region $\mathrm{P}_{3}\left[\mathrm{k}_{2}, \mathrm{k}_{3}\right] ;(4)$ close-to-crack line region $\mathrm{P}_{4}\left[\mathrm{k}_{3}, \mathrm{k}_{4}\right] ;(5)$ crack line region $\mathrm{P}_{5}\left[\mathrm{k}_{4}, 255\right]$.

There is $I=p_{1} \cup p_{2} \cup p_{3} \cup p_{4} \cup p_{5}$ obviously, and $p_{3}, p_{4}, p_{5}$ is in mixing distribution, if you want to depart crack line and background, which means to depart $\mathrm{p}_{3}, \mathrm{p}_{4}, \mathrm{p}_{5}$, but it's impossible to part fragments correctly by the means of adopting single global threshold, which will effect following operation heavily. For this reason, the paper plans to use the following processing steps:

(1) Apply background subtraction for noise deduction, so as to get fragment image similar to the original image.

(2) Mathematical morphology opening filter out the noise point from crack line, like make a statistics of fragment amount.

\section{Extraction of Crack Line}

In practical processing, the extraction of crack line will be effected as the existing problem of low contrast ratio in image. Therefore, this paper makes a primary conduction of histogram equalization to enhance the contrast ratio of image, and then makes advantage of gray scale corrosion to lower the impact of these factors.

Set the gray scale of the original image as $\mathrm{f}$ in $(\mathrm{x}, \mathrm{y})$, and one of changed image as $\mathrm{g}$, the method of strengthening image can be expressed that the gray scale $\mathrm{f}$ in $(\mathrm{x}, \mathrm{y})$ maps to $\mathrm{g}$.

The process of gray scale corrosion is shown as formula (1):

$$
G(x, y)=\min \left\{f\left(x+x^{\prime}, y+y^{\prime}\right)-S\left(x^{\prime}, y^{\prime}\right) \mid\left(x^{\prime}, y^{\prime}\right) \in D s\right\}
$$

In the formula: $S\left(x^{\prime}, y^{\prime}\right)$ is structural element, Ds is the domain of $S\left(x^{\prime}, y^{\prime}\right), G(x, y)$ is the image after gray scale corrosion. 


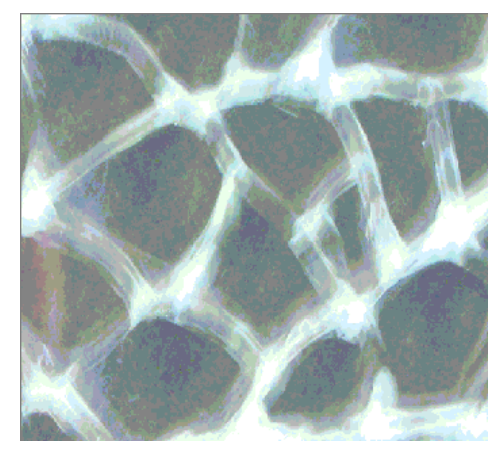

Fig.3: Contrast enhancement

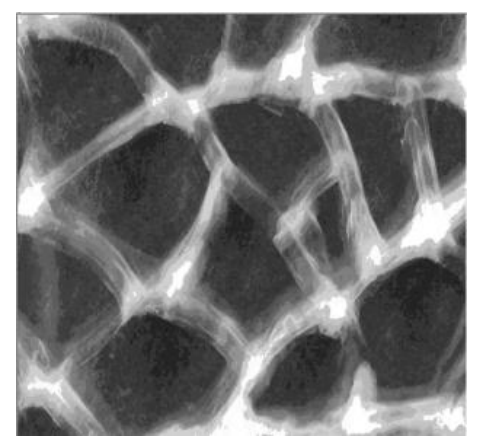

Fig.4: Enhanced gray scale

Fig. 3 increases the width and depth of crack line so as to achieve the purpose of strengthening the contrast ratio of crack line. As the gray scale of pixel is changed in a small scope, the algorithm can protect image detail better.

\subsection{Noise Deduction of Background Subtraction}

The background subtraction algorithm ${ }^{[4]}$ of crack line image noise deduction is to make use of difference of original image and smoothing image, realize the elimination of non-sharp objects. In terms of sharp objects with similar crack line, smoothing operation will change more gray value, but will not make a big change of noise with balanced gray scale and vague edge. Therefore most noise will be eliminated after deduction operation, while the sharp objects like crack line will remain. The background subtraction is as formula (2)

$$
\mathrm{P}^{\prime}(\mathrm{x}, \mathrm{y})=\operatorname{Median}[\mathrm{P}(\mathrm{x}, \mathrm{y})]-\mathrm{P}(\mathrm{x}, \mathrm{y})
$$

In the formula: $\mathrm{P}(\mathrm{x}, \mathrm{y})$ is the gray value of image, which is usually a integer of eight bits, like the integer within the scope of $[0,255]$; Median represents the median filter operation.

\subsection{Niblack Binarization}

The Niblack binarization algorithm is proposed by C.C ${ }^{[5]}$, which is mainly targeted to the easy-ignored problem of global threshold when in an obvious difference of image and background gray scale and its optimization, in the neighborhood of $\mathrm{R} \times \mathrm{R}$, calculates the average value and variance of pixel point, then use below formula to calculate threshold value.

$$
\mathrm{T}(\mathrm{x}, \mathrm{y})=\mathrm{m}(\mathrm{x}, \mathrm{y})+\mathrm{k} \times \mathrm{s}(\mathrm{x}, \mathrm{y})+\mathrm{r}
$$

Among these, the pixel point s coordinates $(x, y), T(x, y)$ is the threshold value of this point, $\mathrm{m}(\mathrm{x}, \mathrm{y})$ is the pixel average value of pixel point in $\mathrm{RR}$ neighborhood, $\mathrm{s}(\mathrm{x}, \mathrm{y})$ is the pixel standard deviation of the point in $\mathrm{R} \times \mathrm{R}$ neighborhood, $\mathrm{k}$ is the correction factor(common value is -0.1 )

In practical procedure, the procedure will make a statistics of surrounding similar pixel's proportion when sampling in $\mathrm{R} \times \mathrm{R}$ neighborhood, as the proportion is bigger than certain quantity, the targeted pixel and surrounding pixel are thought to be the similar pixel. So the correction factor $r$ will be added automatically in the final calculation of threshold value, improve the threshold value of target point, id the target pixel is not identified similarly to surrounding pixel, $r=0$, which means that calculate according to original algorithm rules.

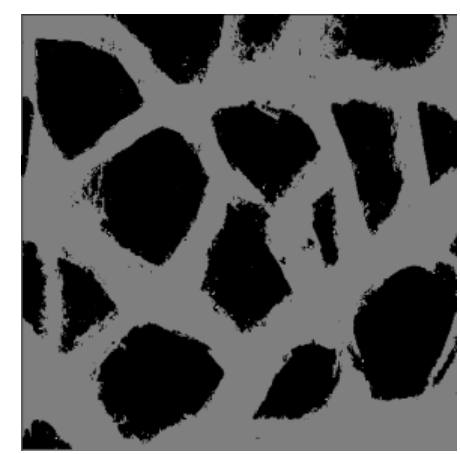

Fig.5: Background subtra

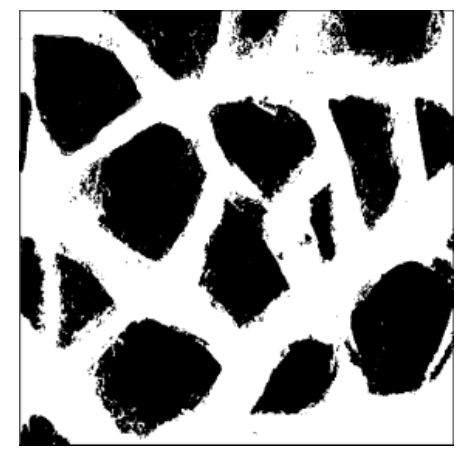

Fig.6: Binarization results 


\subsection{Opening Operation of Mathematical Morphology}

Mathematical morphology consists of algebra algorithm ${ }^{[6-7]}$ operator with a group of morphology, which has their own characteristics in binarization image and gray scale image. On the account of these basic operations, various practical calculation method of mathematical morphology will be deduced and combined, so as to conduct an analysis and disposal of image shape and structure, including image segmentation, characteristic extraction, edge detection, image filtering, image intensification and restoring. The specific algorithm is:

(1) Corrosion: $\mathrm{X} \ominus \mathrm{S}=\{\mathrm{X} \mid \mathrm{S}[\mathrm{X}] \subseteq \mathrm{X}\}$

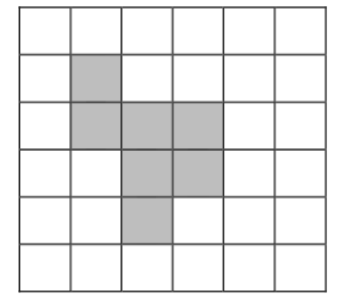

Fig.7: Target image X

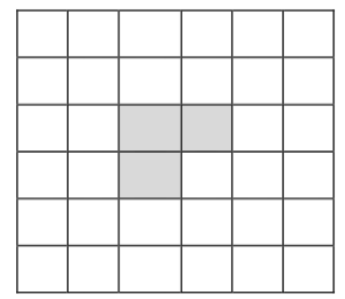

Fig.8: Structural element

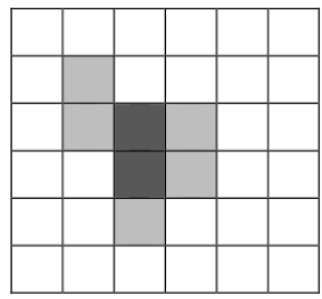

Fig.9: $\mathrm{X} \ominus \mathrm{S}$

Corrosion is equivalent to the intersection of structural element $\mathrm{S}$ in the internal part of target image $\mathrm{X}$, known from above result, corrosion makes the image becomes small.

(2) Expansion: $\mathrm{X} \oplus \mathrm{S}=\{\mathrm{X} \mid \mathrm{S}[\mathrm{x}] \cap \mathrm{X} \neq \emptyset\}$

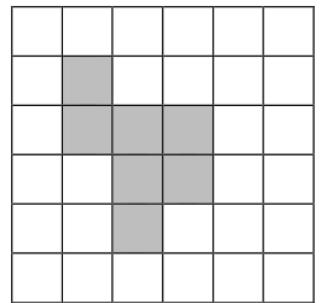

Fig.10: Target image $\mathrm{X}$

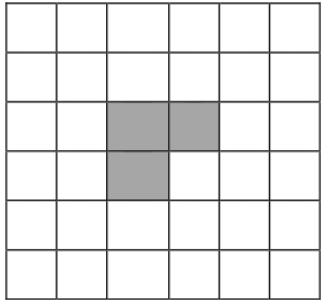

Fig.11: Structural element S

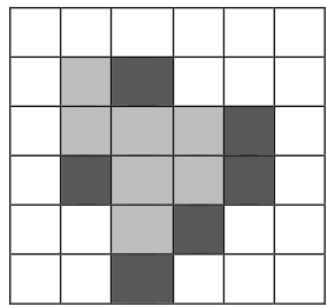

Fig.12: $X \oplus S$

Expansion is the process that merges all background point which is touching object into this object and expand outside of boundary, which can fill the hole of this object.

(3) Closed operation: $X \boxminus S=(X \oplus S) \ominus S$

(4) Opening operation: $X \bigcirc S=(X \ominus S) \oplus S$

Opening operation is the process after corrosion, then expansion, which is used for eliminating small object, departing object in slim point, smoothing the edge of big object but not changing its area obviously at the same time. Seen from the below two images, the small two images on the side of Fig. 14 will be eliminated, at the same time, this image is more smoother than Fig. 13.

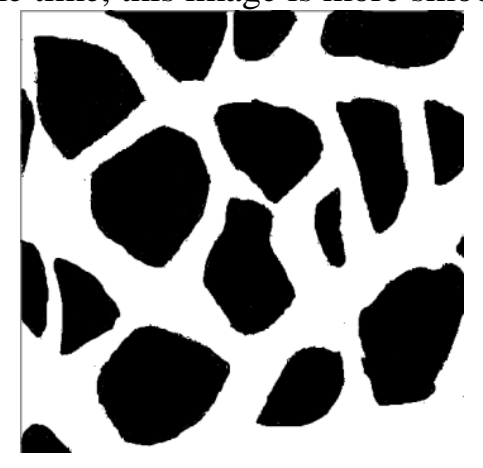

Fig.13: Structural element $13 \times 1$

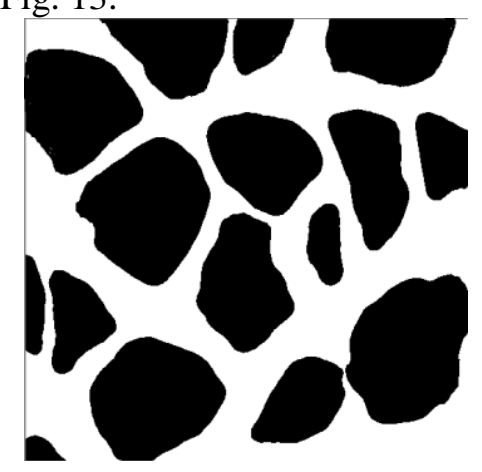

Fig.14: Structural element $20 \times 20$

\section{Crack Line Refining}

Set the pixel value of crack line as 0 , background value as 1 . The following picture is the sketch image of refining algorithm ${ }^{[8]}$. 


\begin{tabular}{|l|l|l|}
\hline$P_{3}(i-1, j-1)$ & $P_{2}(i-1, j)$ & $P_{1}(i-1, j+1)$ \\
\hline$P_{4}(i, j-1)$ & $P_{5}(i, j)$ & $P_{6}(i, j+1)$ \\
\hline$P_{9}(i+1, j-1)$ & $P_{8}(i+1, j)$ & $P_{7}(i+1, j+1)$ \\
\hline
\end{tabular}

Extract a neighborhood of $3 \times 3$ area, set central point as $P_{1}$, whose coordinate is $(i, j)$, the left pixel points in the neighborhood are $\mathrm{P}_{2}, \mathrm{P}_{3}, \ldots, \mathrm{P}_{9}$, if the pixel point meet below four conditions in neighborhood, the central point will be deleted.

(1) $\mathrm{T}\left(\mathrm{P}_{5}\right)=1$;

(2) $2 \leq \mathrm{Z}\left(\mathrm{P}_{5}\right) \leq 6$;

(3) $\left(1-\mathrm{P}_{2}\right)\left(1-\mathrm{P}_{4}\right)\left(1-\mathrm{P}_{8}\right)=0$ or $\mathrm{T}\left(\mathrm{P}_{1}\right)=1$;

(4) $\left(1-\mathrm{P}_{2}\right)\left(1-\mathrm{P}_{4}\right)\left(1-\mathrm{P}_{6}\right)=0$ or $\mathrm{T}\left(\mathrm{P}_{4}\right)=1$;

Among these, $\mathrm{Z}\left(\mathrm{P}_{1}\right)$ is the point amount of pixel value 0 in $\mathrm{P}_{2}, \mathrm{P}_{3}, \ldots, \mathrm{P}_{9}, \mathrm{~T}(\mathrm{P})$ is the times pixel value with a change from 0 to 1 in the neighborhood 8 of $\mathrm{P}$ point according to the ordering of anti-clockwise direction.

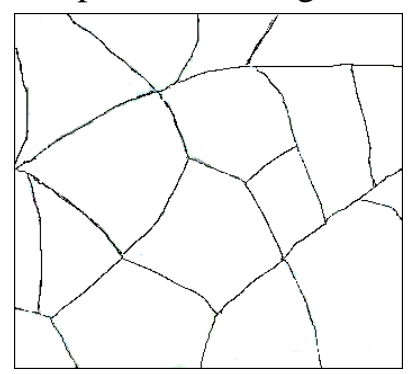

Fig.15: Thinning results

\section{Result Analysis}

In order to verify the high efficiency of algorithm in this paper, make use of configuration of notebook in following Table 1, and select randomly the 10 pieces of sample images collected from fragmentation test and conduct experiment, and make an analysis with other methods, the detailed data is shown in Table 2

Table 1: Configuration

\begin{tabular}{ll}
\hline configuration & specification \\
\hline mainboard & Lenovo 0578MDC \\
CPU & Intel i3 CPU 2.53GHz \\
rigid disk & Hitachi 320GB 5400 turns \\
RAM & Sumsung DDR3 1066MHz 2GB \\
Graphics card & ATI Mobility Radeon HD 545v 512M \\
\hline
\end{tabular}

Table 2: Experimental data of fragment status

\begin{tabular}{|c|c|c|c|c|c|c|c|}
\hline \multirow[b]{2}{*}{$\begin{array}{l}\text { samp } \\
\text { le }\end{array}$} & \multirow[b]{2}{*}{$\begin{array}{l}\text { real } \\
\text { fragment } \\
\text { quantity }\end{array}$} & \multicolumn{2}{|c|}{$\begin{array}{l}\text { traditional } \\
\text { algorithm }\end{array}$} & \multicolumn{2}{|c|}{$\begin{array}{l}\text { Literature } \\
\text { algorithm }\end{array}$} & \multicolumn{2}{|c|}{$\begin{array}{l}\text { algorithm of this } \\
\text { paper }\end{array}$} \\
\hline & & $\begin{array}{l}\text { Quan } \\
\text { tity } \\
\text { statist } \\
\text { ics }\end{array}$ & $\begin{array}{l}\text { Operati } \\
\text { ng time } \\
(\mathrm{ms})\end{array}$ & $\begin{array}{l}\text { Quant } \\
\text { ity } \\
\text { statist } \\
\text { ics }\end{array}$ & $\begin{array}{l}\text { Operati } \\
\text { ng time } \\
(\mathrm{ms})\end{array}$ & $\begin{array}{l}\text { Quant } \\
\text { ity } \\
\text { statist } \\
\text { ics }\end{array}$ & $\begin{array}{l}\text { Operati } \\
\text { ng time } \\
(\mathrm{ms})\end{array}$ \\
\hline 1 & 21 & 20 & 190.3 & 21 & 230.7 & 21 & 89.6 \\
\hline 2 & 33 & 30 & 201.2 & 33 & 256.3 & 32 & 100.2 \\
\hline 3 & 19 & 19 & 181.5 & 19 & 236.1 & 19 & 85.4 \\
\hline 4 & 47 & 45 & 230.4 & 46 & 280.6 & 47 & 126.7 \\
\hline 5 & 28 & 28 & 198.3 & 28 & 246.3 & 28 & 89.9 \\
\hline 6 & 59 & 58 & 257.9 & 59 & 303.5 & 58 & 130.4 \\
\hline 7 & 42 & 41 & 235.8 & 42 & 276.1 & 42 & 128.9 \\
\hline 8 & 75 & 73 & 280.6 & 75 & 328.6 & 74 & 143.6 \\
\hline 9 & 68 & 65 & 271.9 & 68 & 319.7 & 67 & 140.5 \\
\hline 10 & 53 & 50 & 255.3 & 53 & 301.6 & 53 & 130.1 \\
\hline
\end{tabular}


Table 3: The accuracy rate of three algorithms and average operating time

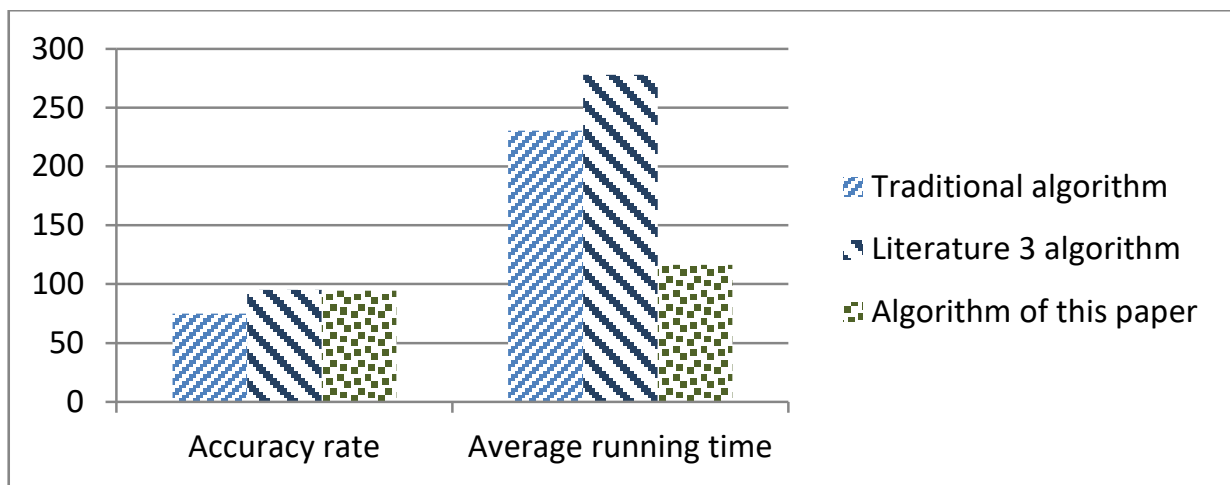

Seen from the table 2, as the sensibility of image edge information to mathematical morphology, the detection of image edge fragment quantity will be influenced; there is error within the scope in the real fragment quantity and detected fragment quantity. The statistics result show, the average accuracy of fragmentation test result from this algorithm is $94.4 \%$, which is a little lower than the $95.1 \%$ of literature 3 algorithm, but the operating time is obviously better than its algorithm. Above image has a direct demonstration on the comparison of accuracy of three algorithms and operating time

\section{Conclusion}

The automatic algorithm of safety glass crack line makes a precise detection of crack line of fragment, marks off fragment region, makes a statistics of fragment quantity. While collecting fragment image, the geometric distortion of image may be caused by reasons like camera shooting angle, when the real size and information are not uniform which are represented by all points in the image, the algorithm can't be used directly and fragment image should be corrected in the early stage.

\section{Reference}

[1] R.C. Gonzalez, R,E. Woods. Digital Image Processing. 3 ed [M]. Beijing: Electronic Industry Press,2011,28(4):484-486

[2] T.M. Tanaka. Computer and machine vision: Theory, algorithms, practicalities-E. R. Davies [J]. Waltham: Academic Press, 2014.

[3] Xq. Zhou, Xh. Liu, Xw. Zhang. The Detection and Recognition of Safety Glass Fragment [J], Chinese Graphic Image Journal, 2007, 12(8):1401-1406.

[4] L. Yang. Research on Pedestrian Detection Using Background Subtraction and Simple Behaviors Recognition[D].Beijing: Beijing Jiaotong University,2010.

[5] C. Akinlar, C. Topal. EDCircles: A real-time circle detector with a false detection control [M]. Elsevier Science Inc, 2013, 46(3): 725-740.

[6] Jy. Cao. The General Summary of Entropy Method of Image Segmentation [J]. Pattern Recognition and Artificial Intelligence, 2012, 25(6):958-971.

[7] Zy. Li, Cc. Liu. Image thresholding based on human visual perception and isoperimetric theory [J]. Chinese Image Graphics Journal, 2011, 16(3):370-376.

[8] J. Li, Yy. Peng, Ca. Yuan. Edge thinning based on mathematical morphology thinning algorithm[J].Journal of Computer Applications, 2012, 32(2):514-516. 